\title{
The effect of short delays in punishment on an immediately rewarded response in humans '
}

M. D. VOGEJ_SPROTT

UNIVERSITY OF WATERLOO

Four groups of 22 human Ss were trained on a button-pressing response for immediate reward (money). Following acquisition training, Ss received punishment (electric shock) as well as reward for the response. One group $\left(G_{0}\right)$ received immediate punishment, $G_{10}$ received punishment $10 \mathrm{sec}$ after the rewarded response, $G_{20}$ and $G_{30}$ received punishment delayed $20 \mathrm{sec}$ or $30 \mathrm{sec}$, respectively. $G_{0}$ displayed more response suppression than the three groups receiving delayed punishment but the delay groups did not differ from each other.

Suppression of an immediately rewarded response by delayed punishment (DP) recently was examined using punishment delays of $0 \mathrm{sec}, 30 \mathrm{sec}, 60 \mathrm{sec}$, or 120 sec (Banks \& Vogel-Sprott, 1965). Immediate punishment (i.e., 0 sec DP) achieved significantly more suppression than punishment delayed 30,60 , or $120 \mathrm{sec}$. Although response suppression progressively decreased as punishment delay was increased from 30 to $120 \mathrm{sec}$, the differences between these treatments was not significant. Since many $\mathrm{Ss}$ in the longer delay groups obtained the maximum response score, Banks and Vogel-Sprott suggested that the lack of significant differences between delay conditions might be attributed to a low celling effect on their scores. Thus, while their evidence is in line with the notion of a gradient effect of DP, their study actually provides no conclusive evidence for this phenomenon. Since the greatest difference in response suppression occurred between immediate and $30 \mathrm{sec}$ DP, an investigation of DP intervals from 0 sec to 30 sec could provide additional relevant information to guide an interpretation of the effects of DP. The present study is designed to compare the suppression of a rewarded response under immediate puntshment with that obtained by punishment delays of $30 \mathrm{sec}$ or less.

Method

Eighty-eight undergraduate students at the University of Waterloo were assigned randomly to four groups of 22 Ss each.

The apparatus is fully described elsewhere (Banks \& Vogel-Sprott, 1965). The $S$ was informed that he would have a number of trials on a button-pressing "game" for money which he could keep. He was permitted one response per trial and a response was defined as pressing the four buttons on his response panel. He must respond on each trial, but he could press the buttons in any order he wished. He was instructed to work on a digit symbol task between trials "just for something to do," while he was waiting for the next trial to begin. This task served merely to control and standardize Ss' intertrial activity and digit symbol performance was not scored. The $E$ then attached finger electrodes to S's nondominant hand with the comment that he might sometimes receive an unpleasant electric shock (2.25 $\mathrm{mA}$ for .10 sec) and, if he found a way of working to avoid shock, he could do so if he wished.

The experiment began with acquisition trials. A trial commenced with the onset of a green signal light on the response panel and terminated with S's fourth button press. An intertrial interval of $8 \mathrm{sec}$ was employed. The response (e.g., 4-1-2-3) which S displayed on his fifth trial received a penny from a reward dispenser. This response, termed the "goal response," received immediate reward whenever it was emitted on subsequent trials throughout the entire experiment. Training was continued until a criterion total of 10 goal responses was displayed.

Twenty punishment trials immediately followed the acquisition period. During these trials, punishment as well as reward was administered for the goal response whenever it was displayed. Immediate punishment(i.e., 0 sec DP) was administered to $\mathrm{Ss}$ in one group $\left(\mathrm{G}_{0}\right)$. Another group $\left(G_{10}\right)$ received punishment 10 sec after the rewarded goal response was emitted, and Groups $G_{20}$ and $G_{30}$ received punishment delayed for 20 and $30 \mathrm{sec}$, respectively. Under punishment training, a trial terminated either with punishment, or with a nonpunished response. A 35 sec intertrial interval was employed during these trials to ensure that punishment was closer in time to the goal response than to the onset of the next trial. The number of goal responses occurring during these 20 punishment trials was recorded.

At the conclusion of the experiment, each $\mathrm{S}$ was asked if he knew the reason for the occurrence of punishment.

\section{Results and Discussion}

The mean number of goal responses on 20 punishment trials for groups under each DP condition is presented in Fig. 1. The error term from the overall vartance analysis of these scores was employed to assess the difference between individual group pairs. $G_{0}$ differs from $G_{10}(p<.05)$, from $G_{20}(p<.10)$ and from $G_{30}(p<.05)$. The three delay groups, however, do not differ from each other $(p>.50)$

The observation that punishment delayed 10,20 , or 30 sec after the rewarded response achieves less suppression than immediate punishment, agrees with the general notion that delayed punishment is less effective than Immediate punishment of a response. In addition, 


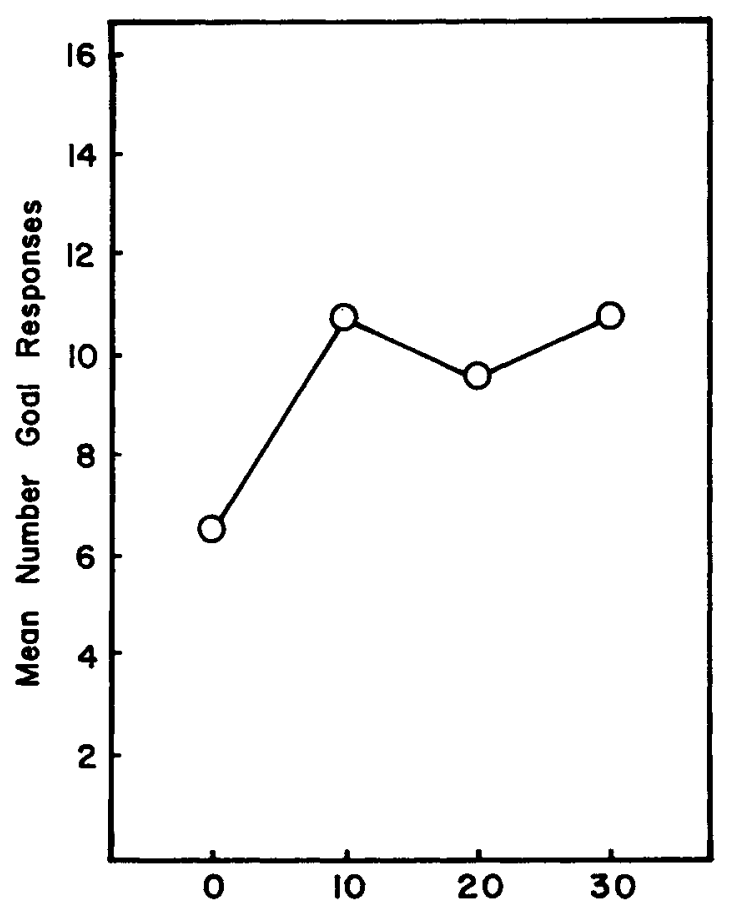

Punishment Delays (in seconds)

Fig. 1. Goal responses during punishment as a function of punishment delay.

this finding is in line with other human studies which report a significant difference in response suppression between immediate and $30 \mathrm{sec}$ DP (Banks \& VogelSprott, 1965) and between immediate and $10 \mathrm{sec}$ DP (Hare, 1966). The present study, however, provides no evidence for a gradient effect of delayed punishment within the 10 to $30 \mathrm{sec}$ range. The inability to detect differences in response suppression with these delays cannot arise because of any ceiling effect on the scores, since the means for the delay groups are all well below the maximum score of 20 which could be obtained.

Since response suppression in animals has been found to alter as a function of 10, 20, and $30 \mathrm{sec}$ DP (Kamin, 1959), the relative insensitivity of human behavior to the same delays in punishment is of considerable interest. Vogel-Sprott $(1966,1967)$ has reported that Ss who emit goal responses on all trials under 30 sec DP typically are unable to state the causal association between their response and punishment at the conclusion of the experiment. This evidence could imply that a knowledge of the causal relation between one's response and punishment may mediate suppression independently of the actual delay in punishment. The Ss' replies to the postexperimental question about shock are pertinent here. Only six of the $88 \mathrm{Ss}$ in this study failed to state that their goal response caused punishment. The mean number of punished responses for these Ss was 19, and five of these Ss obtained the maximum score of 20 . One of these $S s$ belonged to $G_{10}$, two were obtained in $G_{20}$, and the remaining three Ss occurred in $G_{30}$. All $\mathrm{Ss}$ in $\mathrm{G}_{0}$ correctly verbalized the causal association between the goal response and punishment. Since Ss in this experiment were not told that punishment was administered for the goal response, this knowledge could be acquired only during the punishment trials. The observation that the percentage of Ss with this information decreased progressively with each increase in DP may suggest that this knowledge is acquired more quickly when punishment more closely follows the response.

The assumption that a mediating link between response and punishment is an important factor determining response suppression in humans holds interesting implications. For example, it suggests that any gradient effect of DP on response suppression may be detected only when comparisons are made between delays which differ by more than $30 \mathrm{sec}$, and any such differences might be eliminated by providing $S$ with this mediator prior to the onset of punishment.

\section{References}

BANKS, R. K., \& VOGELSPROTT, M. D. The effect of delayed punishment on an immediately rewarded response in humans. $J$. exp. Psychol., 1965, 70, 357-359.

HARE, R. Suppression and recovery of a human response as a function of the temporal order of reward and punishment. Psychon. Sci, 1966, 5, 49-50.

KAMIN, L. The delay of punishment gradient. J. comp. physiol Psychol, 1959, 52, 434-437.

LINDQUIST, E. F. Design and analysis of experiments. Boston: Houghton Mifflin Co., 1956.

VOGELSPROTT, M. A classical conditioning procedure to control suppression of a rewarded response punished after delay. Psychol, Rep., $1966,19,91-98$.

VOGEL-SPROTT, M. Individual differences in the suppressing effect of punishment on a rewarded response in alcoholics and nonalcoholics. Quart. J. Stud. Alcohol, 1967, 28, 33-42.

Note

1. This research was supported by Grant APA-93 from the National Research Council. Assistance on this research was provided by Barbara Mitchell and Irwin Altrows. 